\title{
Knowledge Regarding Diabetes among Women Residing In Kolkata, West Bengal, India.
}

\author{
Sonali Majumdar (Das)*, Sarmistha Mukherjee**, Anil Baran \\ Singhamahapatra***, Munna Das****, Saibendu Kumar Lahiri***** \\ *Associate Professor, Department of Physiology, R.G.Kar Medical College,University of Health Sciences, \\ Kolkata,India \\ **Senior Divisional Medical Officer,B.R.Singh Hospital \& Centre for Medical Research \\ \&Education, Kolkata,India \\ *** Head of Department,Professor,Department of Physiology, R.G.Kar Medical College, University of Health \\ Sciences, Kolkata,India \\ ****Senior Consultant, Department of Cardiology, WestBank Hospital, Howrah, India \\ *****Head of Department,Professor,Department of Community Medicine, R.G.Kar Medical College, \\ University of Health Sciences, Kolkata,India
}

\begin{abstract}
Prevalence of Diabetes Mellitus has increased dramatically in India especially Eastern region which has insufficient resources to combat the scourge. Women are the worst sufferers of the condition, but limited study exists regarding knowledge of Diabetes among the resident women. Kolkata being the most important city of Eastern India, so the present study was undertaken to assess knowledge regarding Diabetes among women residing in Kolkata.

An observational descriptive study of case- control design was initiated after getting Ethical clearance from Institutional Ethics Committee, R.G.Kar Medical College, Kolkata. Women aged between 18 to 74 years residing in Kolkata were chosen by Simple Random Sampling and interviewed with a pre-designed and pretested schedule. Only those who reported to have tested their blood glucose within last 2 years were included. The data were analysed using Student's t and Fisher's Exact tests.

Out of total of 30 women, nine were diabetic while 21 were non-diabetic. Knowledge of disease and its complications was found to be unsatisfactory in both groups. However with respect to overall knowledge about complications of Diabetes, especially that relating to cardiac problem the diabetic group scored more $\{p<0.05\}$.Hence there is need for creating more awareness regarding the disease in Eastern India.
\end{abstract}

Key words: Diabetes, Knowledge, Kolkata, West Bengal, Women.

\subsection{Nature of the problem}

\section{Introduction}

India currently has 50 million diabetics, of which $6-12 \%$ resides in urban areas. [1]

\subsection{Previous work}

Studies have been conducted in other parts of the country regarding knowledge of Diabetes and found that in comparison to men, women have poor knowledge about the disease with fewer women getting proper treatment for the same. [2], [3] Balagopal et. al. has proved that knowledge regarding Diabetes is important for management of the disease. [4] Epidemiological data about women of Eastern India is limited. [5], [6]

\subsection{Purpose of the study}

Thus an observational descriptive study with case control design was undertaken to assess the knowledge regarding Diabetes among women residing in Kolkata.

\subsection{Contribution of the study}

Promote awareness regarding the disease and health promotion

\section{Materials And Methods}

The study was commenced only after getting Ethical clearance from the Ethical committee, R. G. Kar Medical College, Kolkata, India.

\subsection{Study type}

Observational descriptive study 
Knowledge Regarding Diabetes Among Women Residing In Kolkata, West Bengal, India.

\subsection{Study design}

Case control design

\subsection{Study area}

Out of total 141 wards of Kolkata Municipal Corporation (KMC) ward Number 126 was selected by Simple Random Sampling (SRS) method.

\subsection{Study population}

Women residing in ward 126 as per inclusion and exclusion criteria by SRS technique.

\subsubsection{Inclusion criteria-}

i. $\quad$ Aged 18 to 74 years[7]

ii. Reported to have tested their blood glucose within 2 years of the start of study

This particular age group was considered as it was the most active years of women's life. [7]

\subsubsection{Exclusion criteria}

i) Subjects too ill to participate / unwilling to participate

ii) Subjects more than 74 years of age \& less than 18 years of age. [7]

\subsection{Study period}

From July 2012 to December 2013.

\subsection{Sampling method}

Out of total 141 wards of KMC, ward number 126 was chosen through SRS. Initially a total of 68 ladies were selected through SRS from the enrolled women in 18-74 years age group in the current voter list 2011 using random.org software. Data were collected in the pre-designed \& pre-tested schedule. Out of 68 women, 9 were found to be diabetic, rest, fifty-seven were non- diabetic. Twenty-one women were chosen from the non diabetic group who matched in terms of age, BMI, years of education, social class, physical exercise during leisure time and occupation with the diabetic group. Of the diabetic women, 8 were untreated and 1 was treated for complications.

\subsection{Parameters}

A pre designed \& pre tested schedule was administered to every consenting individual after pre testing in twenty five subjects prior to commencement of the study. Socio demographic profile like age, monthly household income, years of education, family history of diabetes, leisure time- physical exercise and clinical measurements like weight, height, waist circumference (WC), hip circumference, systemic blood pressure (BP) using standardized protocols and instruments were taken. [8], [9] From the above Body Mass Index (BMI), Waist -Hip ratio (W/H ratio) and Mean Arterial Pressure (MAP) was calculated.

From height and weight, Body Mass Index (BMI) was estimated in $\mathrm{kgs} / \mathrm{m}^{2}$. BMI between 18.5 to 22.9 $\mathrm{kgs} / \mathrm{m}^{2}$ was considered normal for Asians. Women with BMI 23 to $24.9 \mathrm{~kg} / \mathrm{m}^{2}$ were termed overweight while $\geq$ $25 \mathrm{~kg} / \mathrm{m}^{2}$ were termed obese. [8]

BP was expressed as Systolic Blood Pressure (SBP)/Diastolic Blood Pressure (DBP) in millimeters of Mercury (mmHg). SBP between 100 to less than $120 \mathrm{~mm} \mathrm{Hg}$ and DBP between 60 to less than $80 \mathrm{mmHg}$ was considered normal. Pre hypertension when SBP was 120 to $139 \mathrm{mmHg}$ and or DBP was 80 to $89 \mathrm{mmHg}$. Hypertension when SBP $\geq 140 \mathrm{mmHg}$ and or DBP $\geq 90 \mathrm{mmHg}$. [9]

Scoring of questionnaire regarding knowledge of diabetes was done with correct answer having score 1 and incorrect response having score 0 . Total score was calculated out of 8 . Score of 7 out of 8 and above was considered a good score [10]

The present study was undertaken to assess whether the knowledge about diabetes was good among diabetic women as compared to non diabetic women.The hypothesis being tested was that knowledge regarding diabetes was good in urban literate women of Kolkata.

\subsection{Study technique:}

Out of 68 women, nine were diabetic and termed as cases and compared with 21 women who were non-diabetic otherwise age, BMI and socio economic status matched.

The data were analyzed with MS Excel sheet and appropriate statistical analysis by Student's t test, Fisher's Exact test were done using Graph Pad Quick calc software with P value $<0.05$ considered to be statistically significant. 
Knowledge Regarding Diabetes Among Women Residing In Kolkata, West Bengal, India.

\section{Results}

TABLE 3.1 Socio-Demographic profile of the study population

\begin{tabular}{|l|l|l|l|}
\hline Parameters & $\begin{array}{l}\text { Diabetic group } \\
\mathbf{n = 9} \\
\text { Mean } \pm \text { SD }\end{array}$ & $\begin{array}{l}\text { Non -diabetic group } \\
\mathbf{n = 2 1} \\
\text { Mean } \pm \text { SD }\end{array}$ & p- Value \\
\hline Age (in years) & $53.11 \pm 13.21$ & $48.19 \pm 10.59$ & 0.2769 \\
\hline Education (in years) & $11.66 \pm 3.67$ & $11.28 \pm 3.74$ & 0.7995 \\
\hline
\end{tabular}

Table 3.1 shows that the mean age for diabetic group being $\mathbf{5 3 . 1 1} \pm \mathbf{1 3 . 2 1}$ years while that for nondiabetic group being $48.19 \pm 10.59$ years and all the subjects were literate with mean years of education for diabetic group being $11.66 \pm 3.67$ years and for non diabetic group being $11.28 \pm 3.74$ years. On applying $\mathrm{t}$ test the results were similar in the two groups.

TABLE 3.2 Socio-Demographic profile of the study population

\begin{tabular}{|c|c|c|c|c|c|c|}
\hline \multirow{2}{*}{\multicolumn{2}{|c|}{ Parameters }} & \multirow{2}{*}{\multicolumn{2}{|c|}{ Diabetic subjects $=9$}} & \multicolumn{2}{|c|}{ Nondiabetic subjects, $\mathrm{n}=21$} & \multirow{2}{*}{$\begin{array}{l}\mathrm{p} \text { - value } \\
\mathrm{P}=1\end{array}$} \\
\hline & & & & & & \\
\hline 1.Occupational Status & Homemakers & Total Number & $\%$ & $\begin{array}{l}\text { Total Number } \\
14\end{array}$ & $\begin{array}{l}\% \\
66.66 \\
\end{array}$ & \\
\hline & Working Women & 3 & 33.34 & 7 & 33.34 & \\
\hline \multirow[t]{3}{*}{ 2.Social class[11] } & High & 2 & 22.22 & 6 & 28.57 & $p>0.05$ \\
\hline & Middle & 4 & 44.44 & 9 & 42.85 & $\mathrm{p}>0.05$ \\
\hline & Poor & 3 & 33.33 & 6 & 28.57 & $\mathrm{p}>0.05$ \\
\hline \multirow{2}{*}{$\begin{array}{l}\text { 3.Leisure time -physical } \\
\text { exercise }\end{array}$} & Yes & 5 & 55.55 & 11 & 52.38 & $\mathrm{P}>0.05$ \\
\hline & No & 4 & 44.44 & 10 & 47.61 & \\
\hline \multirow[t]{2}{*}{ 4.Relative with diabetes } & Yes & 4 & 44.44 & 4 & 19.04 & $\mathrm{P}=0.195$ \\
\hline & No & 5 & 55.55 & 17 & 80.95 & \\
\hline
\end{tabular}

Table 3.2,shows that six out of nine of them diabetics were homemakers(66.66\%), 14 out 21 of the nondiabetics $(66.66 \%)$ were homemakers. So far as social classification is concerned, 5 out $9(55.55 \%)$ of diabetic and 10 out $21(47.61 \%)$ of non diabetic belonged to middle class. Five out of nine diabetic subjects $(55.55 \%)$ and non-diabetic group 11 out $21(52.38 \%)$ did not participate in leisure time- physical exercise.

Four out 9 diabetic women had a relative with diabetes $(44.44 \%)$ while 4 out of 21 non diabetic had a relative (either or both parents or siblings) with diabetes (19.04\%). The occupation, social class, whether they were involved in leisure time - physical exercise and whether they had a relative with diabetes was found to be same in both the groups as per Fisher's Exact test.

TABLE 3.3 Anthropometric and clinical measurements of the study population

\begin{tabular}{|c|c|c|c|}
\hline Parameters & $\begin{array}{l}\text { Diabetic group } \\
\mathrm{n}=9 \\
\text { Mean } \pm \mathrm{SD}\end{array}$ & $\begin{array}{l}\text { Non -diabetic group } \\
\text { n=21 } \\
\text { Mean } \pm \text { SD }\end{array}$ & P-value \\
\hline Height & $1.53 \pm 0.058$ & $1.53 \pm 0.060$ & $\mathrm{P}=1$ \\
\hline Weight & $60.75 \pm 7.40$ & $54.61 \pm 9.43$ & $\mathrm{P}=0.09$ \\
\hline BMI ( kg/m2) & $25.86 \pm 3.45$ & $23.34 \pm 3.9$ & $\mathrm{P}=0.1051$ \\
\hline Waist circumference $(\mathrm{cm})$ & $106.75 \pm 26.16$ & $89.80 \pm 16.61$ & $\mathrm{P}=.0406^{*}$ \\
\hline Hip circumference $(\mathrm{cm})$ & $97.55 \pm 16.73$ & $93.52 \pm 15.53$ & $\mathrm{P}=0.5294$ \\
\hline W/H ratio & $1.12 \pm 0.28$ & $0.95 \pm 0.07$ & $\mathbf{P}=0.013 *$ \\
\hline $\mathrm{SBP}(\mathrm{mmHg})$ & $126.93 \pm 15.39$ & $117.88 \pm 15.07$ & $\mathrm{P}=0.145$ \\
\hline $\mathrm{DBP}(\mathrm{mmHg})$ & $74.35 \pm 7.43$ & $72.86 \pm 9.12$ & $\mathrm{P}=0.669$ \\
\hline MAP $(\mathrm{mmHg})$ & $90.63 \pm 9.39$ & $87.61 \pm 10.39$ & $\mathrm{P}=0.459$ \\
\hline
\end{tabular}

$* \mathrm{P}<0.05$, statistically significant

Table 3.3, refers to the Body Mass Index (BMI) of the study population with mean BMI of diabetic group was $25.86 \pm 3.45 \mathrm{~kg} / \mathrm{m} 2$ while that for non-diabetic group being $23.34 \pm 3.9 \mathrm{~kg} / \mathrm{m} 2$. Mean Waist circumference for diabetic group was $106.75 \pm 26.16 \mathrm{~cm}$ while that for non-diabetic group being 89.80 $\pm \mathbf{1 6 . 6 1} \mathrm{cm}$ with $\mathrm{p}$ value $=\mathbf{0 . 0 3 4 7}$ and significant. Mean Waist $/$ hip ratio for the diabetic group was $1.12 \pm$ $\overline{0} .28$ and for non-diabetic group was $0.95 \pm 0.07$ and are significantly different with $P=0.013$. Hip circumference of the non diabetic group is $93.52 \pm 15.53 \mathrm{~cm}$ and that of diabetic group is $97.55 \pm 16.73 \mathrm{~cm}$ and does not show significant difference.

Mean Systolic Blood Pressure (SBP) for diabetic group is $126.93 \pm 15.39 \mathrm{~mm} \mathrm{Hg}$ and for the non- 
Knowledge Regarding Diabetes Among Women Residing In Kolkata, West Bengal, India.

diabetic group is $117.88+15.07 \mathrm{~mm} \mathrm{Hg}$. Mean Diastolic Blood Pressure (DBP) for diabetic group is $74.35 \pm$ $7.43 \mathrm{mmHg}$ and for non-diabetic group is $72.86 \pm 9.12 \mathrm{mmHg}$. Mean Arterial Blood Pressure (MAP) for the non diabetic group was $87.61 \pm 10.39 \mathrm{~mm} \mathrm{Hg}$ while that for diabetic group was $90.63 \pm 9.39 \mathrm{mmHg}$. Though the values were slightly higher in diabetic group but were not statistically significant.

TABLE 3.4: Knowledge Regarding Diabetes

\begin{tabular}{|l|l|l|l|l|}
\hline Items Interrogated: & \multicolumn{2}{l|}{$\begin{array}{l}\text { Diabetic group } \\
\mathbf{n = 9}\end{array}$} & \multicolumn{2}{l|}{$\begin{array}{l}\text { Non -diabetic group } \\
\mathbf{n}=\mathbf{2 1}\end{array}$} \\
\cline { 2 - 5 } & $\begin{array}{l}\text { Number of } \\
\text { Correct } \\
\text { Responses }\end{array}$ & $\%$ & $\begin{array}{l}\text { Number of Correct } \\
\text { Responses }\end{array}$ & $\%$ \\
\hline $\begin{array}{l}\text { A person can have diabetes but be } \\
\text { unaware of it }\end{array}$ & 5 & 55.55 & 15 & 71.42 \\
\hline $\begin{array}{l}\text { Diabetes can harm a person's body before } \\
\text { diagnosis }\end{array}$ & 8 & 88.88 & 17 & 80.95 \\
\hline $\begin{array}{l}\text { Overall Knowledge: Long term } \\
\text { complications of diabetes }\end{array}$ & 7 & 77.77 & $\mathbf{6}$ & $\mathrm{P}=1$ \\
\hline $\begin{array}{l}\text { The age group in which diabetes is most } \\
\text { common }\end{array}$ & 4 & 44.44 & 10 & $\mathbf{2 8 . 5 7}$ \\
\hline Diabetes is curable & 5 & 55.55 & 18 & 47.61 \\
\hline
\end{tabular}

$* \mathrm{P}<0.05$, statistically significant

TABLE 3.5 : Long term complications of diabetes

\begin{tabular}{|l|l|l|l|l|l|}
\hline $\begin{array}{l}\text { Knowledge regarding } \\
\text { Individual } \\
\text { Complications }\end{array}$ & $\begin{array}{l}\text { Diabetic group } \\
\mathbf{n = 9}\end{array}$ & $\begin{array}{l}\text { Non -diabetic group } \\
\text { n=21 }\end{array}$ & p-value \\
\cline { 2 - 6 } & Total number & $\%$ & Total number & $\%$ & \\
\hline Eye & 5 & 55.55 & 5 & 23.08 & $\mathrm{P}=0.115$ \\
\hline Kidney & 5 & 55.55 & 6 & 28.57 & $\mathrm{P}=0.225$ \\
\hline Heart & $\mathbf{3}$ & $\mathbf{3 3 . 3 3}$ & $\mathbf{0}$ & $\mathbf{0}$ & $\mathbf{P}=\mathbf{. 0 2} *$ \\
\hline Foot & 0 & 0 & 0 & 0 & \\
\hline
\end{tabular}

$* \mathrm{P}<0.05$,statistically significant

Only 1out of 21 in non diabetic group (4.76\%) and 1 out 9 of the diabetic group (11.11\%) had heard about a disease called diabetes while the rest responded positively only when the disease was referred by it's more popular name "sugar" disease.

In diabetic group, most of them 7 out $9,(77.77 \%)$ had at least some idea regarding long term complications of diabetes. Of the non-diabetic group, only 6 out 21(28.57\%) were aware of the long term complications of diabetes. On applying Fisher's Exact test the overall knowledge regarding diabetes complications was more in diabetic women in comparison to non diabetics and found to be statistically significant. $P=0.0196$

Most commonly reported complications by the diabetic women being that of eye 5 out $9(55.55 \%)$, kidney 5 out $9(55.55 \%)$ and Heart 3 out 9(33.33\%). In case of non -diabetic women 5 out of 21(23.08\%) reported eye and six out $21(28.57 \%)$ reported kidney problem while none reporting heart \& foot problem as complication of diabetes. With regard to a particular complication only knowledge regarding cardiac problem $(\mathrm{P}=\mathbf{0 . 0 2})$ was found to be significantly different from non -diabetic group. While awareness about eye $(P=0.08)$, foot problem $(P=0.15)$ and kidney problem $(P=0.08)$ was same for both groups.

The median knowledge score for this group was only 5 out of 8 with Inter Quartile Range (IQR) being 3. However this score was higher than that for non-diabetic group which was 4 out of 8 with IQR being 2 . Diabetes knowledge score between the two groups was similar $(p=0.08)$ and not good as the total score was less than 7 out 8 . [10]

\section{Discussion}

In our study 7 out 9 of the diabetic group (55.55\%) and 15 out 21(71.42\%) of non-diabetic group gave correct answer to the question about whether a person can have diabetes but be unaware of it.

However when asked whether diabetes can harm a person's body before diagnosis, 8 out of $9(88.88 \%)$ diabetic group and 17 out $21(80.95 \%)$ of non diabetic group gave affirmative response. Responders who gave the wrong answer felt that as there was no problem so the disease was causing no harm before diagnosis.

On being asked about the age group in which diabetes is most common 4 out 9 of diabetic group $(44.44 \%)$ and 10 out $21(47.61 \%)$ of non diabetic group answered that it was most common above the age of 45years. Others felt that prevalence of diabetes was increasing in younger age group.

Regarding whether diabetes was curable or not 5 out $9(55.55 \%)$ of diabetic \& 18 out $21(85.71 \%)$ of 
non- diabetic group answered correctly. Simple lowering of blood glucose was considered "cure" by the subjects who gave the incorrect answer. Study by Gulabani M. Et. al. had 67 males (66.3\%) and 34 females $(33.7 \%)$ diabetics in the study population. Of the 101 patients, $51(50.5 \%)$ thought that diabetes to be incurable, which is similar to findings in our study. [12]

Correct responses to above four questions was found to be statistically non significant thus responses were same for both groups.

Though it was expected that knowledge regarding the disease would be good in diabetic women on account of them suffering from the same but responses to above questions were same for both diabetic and non diabetic group by Fisher's Exact test with phi coefficient showing poor association $(<0.3)$ with diabetic status and correct responses.

In our study median scores of diabetic group and non- diabetic group was found to be statistically nonsignificant. Awareness regarding diabetes was not good both in diabetic and non diabetic group, score being less than 7/8. [10] Lorga T. et. al. in Thailand found that good knowledge of diabetes was found among already diabetic subjects. [13] However Mohan V. Et. al. found that knowledge was poor among urban and rural population residing in Chennai even among self reported diabetics. [14]

About knowledge regarding long term complications of diabetes, in diabetic group, most of them had at least some idea regarding long term complications of diabetes. The overall knowledge regarding diabetes complications was more in diabetic women in comparison to non diabetics and found to be statistically significant. $\mathbf{P}=\mathbf{0 . 0 1 9 6}$

Our findings were similar to the large scale population based study by Deepa Mohan et. al. in Chennai who observed that even among self reported diabetics, knowledge regarding long term complications of diabetes was poor.[15] Similar findings were reported by Munninarayana et.al ., Singh A. et. al. and Joshi et. al. [7], [16], [17]. Findings of public awareness study by Lee H. L. et. al. In Singapore observed low scores about general knowledge of diabetes but good idea regarding risk factors of diabetes in that population. [18]

With respect to individual complications, our results differ from that of Gulabani M. et. al. who found that diabetic subjects both men and women who attended the diabetic clinic identified eye (90.1\%) followed by kidney $(72.3 \%)$ then heart $(64.4 \%)$ and foot $(57.4 \%)$ as the organs damaged by diabetes, while in our study diabetic women indicated eye and kidney, both 5 out $9(55.55 \%)$ followed by heart, 3 out $9(33.33 \%)$ and foot 0 out $9(0 \%)$ to be affected by the disease. [12]

However awareness about eye and kidney $(\mathrm{P}=0.08)$ and foot problem $(\mathrm{P}=0.15)$ was similar for both groups, while knowledge regarding cardiac problem $(P=0.02)$ was found to be significantly different from non diabetic group.

Potluri R. et. al. (2009) investigated the prevalence of these complications in patients of south-Asian origin in diabetic clinics in the UK and found that the prevalence of micro vascular complications such as retinopathy $(16.3 \%)$, nephropathy $(20.5 \%)$ and neuropathy $(8.4 \%)$ was significantly higher in India. $(\mathrm{p}<0.05)$. Interestingly, macro vascular complications such as cardiovascular disease were significantly more prevalent in Mauritius and the UK compared to India $(\mathrm{p}<0.05)$. Results suggest that micro vascular complications are higher in India due to poorer diabetic control. [19]

The knowledge regarding complications are important as, though the prevalence of diabetes is roughly equal in both male and females but Indian women are uniquely and often more severely affected by complications of diabetes.[3]

Regarding clinical and anthropometric findings, other studies of India have found that type 2 diabetes may be complicated by hypertension and obesity but in our study though mean SBP and mean BMI was higher in diabetic group $126.93 \pm 15.39 \mathrm{mmHg}$ than non diabetics $117.88+15.07 \mathrm{mmHg}$ and $25.86+3.45 \mathrm{~kg} / \mathrm{m} 2 \mathrm{in}$ diabetics and $23.34+3.9 \mathrm{~kg} / \mathrm{m} 2$ in non-diabetics but was found to be statistically non significant.(20) Waist circumference, waist -hip ratio was however found to be significantly different in diabetic as compared to nondiabetic group. Our findings were similar to other South Asian studies in this regard. [21]

With respect to age, occupation, leisure time -physical exercise and family history of diabetes, our findings were similar to other workers. [16], [22]

\section{Conclusion}

Knowledge regarding diabetes is not good even among urban literate women residing in Kolkata so there is an urgent need to create awareness regarding the same.The sample size being small was a limitation of our study, a large scale survey would give better idea regarding the knowledge of diabetes in women. 


\section{References}

[1]. Diabetes Atlas 3rd edition, International Diabetes Federation, 2006, 5

[2]. M.Legato et al, "Gender- specific care of patients with diabetes: Review and Recommendations", Gender Medicine, 3, 2006,131.

[3]. A. Ghaffar et al, "Burden of non-communicable diseases in South Asia", BMJ, 328, 2004, 807-10.

[4]. P. Balagopal ,N. Kamalamma, T.G.Patel ,R. Misra, A Community-Based Diabetes Prevention and Management Education Program in a Rural Village in India, Diabetes Care, 2008, 31, 1097-1104.

[5]. A.Ghosh, M.Bhagat, Indian diabetic risk score according to menopausal status in Asian Indian women: the Shantiniketan Women Study, Journal of Diabetes, 2009, 1, 140-141.

[6]. R.Pradhan, B.DineshKumar, A. Mitra, Some salient points in type 2 diabetes prevalence in rural Bengal. Ethno Med, 2009, 3,127131 .

[7]. Muninarayana C., Balachandra C., Hiremath S. G., Krishna Iyengar, N. S. Anil , Prevalence and awareness regarding diabetes in rural Tamaka, Kolar, Int J Diab Dev Ctries, Jan-Mar 2010,30(1).

[8]. C.Snehalatha, V. Vishwanathan, A. Ramachandran, Cut off values for normal anthropometric variables in Asian Indian Adults, Diabetes care, 2003, 5, 1380-4.

[9]. T.G.Pickering ,J.E. Hall , L.J.Appel ,B.E. Falkner ,J.Graves ,M.N.Hill ,D.W. Jones ,T.Kurtz ,S.G.Sheps ,E.J.Rocella , Recommendations for blood pressure measurement in humans and experimental animals, part 1: blood pressure measurement in humans: a statement for professionals from the sub committee of Professional and Public Education of the American Heart association council on High Blood Pressure Research, Hypertension, 2005,45,142-161.

[10]. Oregon Diabetes coalition. Oregon progress report on diabetes. Department of Human services, Health services, Oregon diabetes prevention \& control program, Portland, Oregon, 2006.

[11]. B.G.Prasad, Social classification of Indian families, J Indian Medical Assoc, 1961, 37,250-1.

[12]. M.Gulabani,M. John, R.Isaac, Knowledge of diabetes, its treatment and complications amongst diabetic patients in a tertiary care hospital, Indian J Community Med, 2008,33,204-6.

[13]. T.Lorga,M.N. Aung,P.Naunboonruang,P.Thinuan,N.Praipaksin,T.Deesakul et al, Predicting prediabetes in a rural community: a survey among the Karen ethnic community, Thasongyang, Thailand,Int J Gen Med,2012,5,219-225.

[14]. V. Mohan, P.Mathur ,R. Deepa ,M. Deepa ,D.K. Shukla ,G.R. Menon et al, Urban rural differences in prevalence of self-reported diabetes in India--the WHO-ICMR Indian NCD risk factor surveillance, Diabetes Res. Clin. Practice, 2008, 80,159-168.

[15]. D. Mohan ,D. Raj ,C.S. Shanthirani,M Datta ,N.C. Unwin, ,A. Kapur,V. Mohan, Awareness and knowledge of diabetes in ChennaiThe Chennai Urban rural Epidemiology Study, JAPI, 2005, 53 ,283-7.

[16]. A. Singh, P. E. Milton, A. Nanaiah, Prasanna Samuel, Nihal Thomas, Awareness and attitude towards diabetes in the rural population of Arunachal Pradesh , North East India, Indian Journal of Endocrinology and Metabolism,2012, 16 , suppl 1.

[17]. S.R. Joshi, A.K. Das, V.J. Vijay, Mohan V, Challenges in Diabetes care in India: Sheer numbers, lack of awareness and in adequate control, JAPI, 2008, 56,443-450.

[18]. H.L.Wee ,H.K. Ho,S.C.Li, Public awareness of diabetes mellitus in Singapore,Singapore Med J,2002, 43,128-34.

[19]. R.Potluri ,Y. Purmah ,M. Dowlut ,N. Sewpaul ,D. Lavu ,Microvascular diabetic complications are more prevalent in India compared to Mauritius and the UK due to poorer diabetic control, Diabetes Res Clin Pract,. 2009, 86(2):e39-40. doi: 10.1016/j.diabres.2009.08.008. Epub 2009 Sep 18.

[20]. R.Yadav, P. Tiwari, E. Dhanaraj. Risk factors and complications of type 2 diabetes in Asian, Curr Res Information Pharmaceut Sci, $2008,9,8-12$

[21]. R. Jayawardhena,P. Ranasinghe,N.M. Byrne, M. J. Soares, P. Katulanda and A. P Hills ,Prevalence \& trends of diabetic epidemic in South Asia: A systematic review \& meta-analysis, BMC Public Health, 2012 ,12,380.

[22]. V.Chaturvedi, K.S.Reddy, D.Prabhakaran, P.Jeemon, and Development of a clinical risk score in predicting undiagnosed diabetes in urban Asian Indian adults: a population based study, CVD prevention and control, 2008, 3(3), 141-151. 